\title{
An Analysis of Relationship among Income Inequality, Poverty, and Income Mobility, Based on Distribution Functions
}

\author{
Jiandong Chen, ${ }^{1}$ Yaqing $\mathrm{Si}^{2}{ }^{2}$ Fengying $\mathrm{Li}^{3}$, and Aifeng $\mathrm{Zhao}^{1}$ \\ ${ }^{1}$ School of Public Finance and Taxation, Southwestern University of Finance and Economics, Chengdu 611130, China \\ ${ }^{2}$ School of Statistics, Southwestern University of Finance and Economics, Chengdu 611130, China \\ ${ }^{3}$ School of Economic and Mathematics, Southwestern University of Finance and Economics, Chengdu 611130, China \\ Correspondence should be addressed to Fengying Li; lify0308@163.com
}

Received 8 July 2014; Revised 27 August 2014; Accepted 12 October 2014; Published 24 November 2014

Academic Editor: Josip E. Pečarić

Copyright (C) 2014 Jiandong Chen et al. This is an open access article distributed under the Creative Commons Attribution License, which permits unrestricted use, distribution, and reproduction in any medium, provided the original work is properly cited.

\begin{abstract}
Many studies show that the relationship among income inequality, poverty, and income mobility needs to be further discussed. Meanwhile, some researches on Distribution Function offer new perspective and methods to analyze this issue. First, this paper expresses the relationship among the Gini coefficient, poverty ratio, and income mobility of 5 common Distribution Functions through math deduction; this finding cannot be found in relevant literatures. Furthermore, an empirical research result proves that the income distribution of urban residents in the period from 2005 to 2010 fits Log-Logistic Distribution. On the basis of the above analysis and empirical data, the paper explores the relations of income inequality, poverty, and income mobility of urban residents and draws some useful conclusions.
\end{abstract}

\section{Introduction}

With the rapid economic development in China, the degree of residential income inequality has been increasing constantly, which, as well as the consequent poverty and the sluggish income mobility, has been restricting the harmonious and steady development of Chinese society severely. In recent years, income inequality has been a focus of the whole society, leading to narrowing the income gap, eliminating poverty, and improving income mobility as the major challenge for the future development of China. Hence, it becomes particularly significant to reveal the relationship among income inequality, poverty, and income mobility. Although specialists and scholars at home and abroad have carried on massive analysis on residential income inequality so far, the relationship still needs to be studied due to the restriction of data sources. (Compared with other relevant data sources, samples of National Bureau of Statistics have large amount and wide coverage which can be dated back to the early phase of the reform and opening up, so it is a perfect data source for the analysis of residential income distribution. However, the National Bureau of Statistics only provides the limited grouped data, which is the average value of a group. Thus, income inequality would be underestimated if we apply it for the analysis of the residential income gap in China for the inequality is neglected.) And some research related to Distribution Function provides us with exactly brand new perspectives and analysis tools for discussing these issues above, making up the deficiencies of insufficient data, and facilitating the study further related to income distribution as well as other related areas.

The study on the measurement of income concentration ratio conducted by Lorenz [1] (1905) was regarded as a revolution in economics and statistics, resulting in tens of thousands of papers published in magazines about statistics and econometrics and starting the research on the relationship between the Distribution Function and income inequality. According to the literature review of this paper, the expressions of some income inequality indexes like Gini coefficient, Theil index, Pietra index, and Zenga [2] index can be deducted directly on certain Distribution Function. To be specific, Arnold et al. [3] (1987) and other scholars deducted Gini coefficient on Pareto [4] Distribution; Zenga [2] (1984) and Kleiber and Kotz [5] (2003) deducted Zenga index, Pietra index, and Theil index, respectively, on Pareto Distribution; Gini coefficient, Theil index, and Pietra index were deducted by Aitchison 
and Brown [6] (1957) as well as Zenga index deducted by Zenga [2] (1984) on Lognormal Distribution; Gini coefficient and Pietra index were deducted by McDonald and Jensen [7] (1979) as well as Theil index deducted by Salem and Mount [8] (1974) on Gamma Distribution. In addition, McDonald $[9,10](1981,1984)$, Bhattacharjee and Krishnaji [11] (1985), Cronin [12] (1979), Kleiber and Kotz [5] (2003), Butler and McDonald [13] (1989), and other scholars researched the inequality index on generalized Gamma Distribution, LogGamma Distribution, generalized Beta Distribution, and Singh-Maddala Distribution. The research above connects Distribution Function with income inequality in theory, providing a solid theoretical basis for the further study on income inequality.

As mentioned above, there are various means to measure the income inequality. However, Lorenz Curve and the Gini coefficient are the most commonly used Sloman [14] (2000); the Gini coefficient is the most important index to measure or estimate the income inequality Sen [15] (1997), Champernowne and Cowell [16] (1998). Therefore, the Gini ratio is employed in this paper as the index to evaluate income inequality.

Another significant application of Distribution Function in the research of income inequality lies in fitting the residential income distribution. Thanks to the contribution of Pareto [4] (1895) to Distribution Function, he was honored like Lorenz on the statistical study of income distribution (Arnold [17], 1983). Thereafter, many scholars have made a significant contribution in this area, such as Fisk [18] (1961), Harrison [19] (1981), Arnold [17] (1983), McDonald [10] (1984), and Kleiber and Kotz [5] (2003).

As for the relationship between income inequality and poverty, scholars from home and abroad have carried out some helpful exploration, most of whose research achievements were attained by empirical research. Bourguignon [20] (2004) analyzed the internal relationship among poverty, income inequality, and economic growth systematically with the conclusion that the reduced inequality is conducive to poverty reduction. Wan and Zhang [21] (2006) analyzed empirically the impact of the change of income inequality on poverty by Shapley decomposition with the conclusion that the success of poverty reduction in rural areas was mainly attributed to the increase of income as well as the decrease of income inequality. Hu et al. [22] (2007) and other scholars used poverty indication growth curve on the basis of establishing Lorenz Curve on rural residential income to reach the conclusion that the excess of income inequality offsets the effectiveness of poverty reduction in economic growth. Similar results were obtained by Nong and Xubei [23] (2008) with the help of Health and Nutrition Survey data in eight Chinese provinces. In addition, a few scholars theoretically analyzed the relationship between income inequality and poverty. For instance, Takayama [24] (1979) deducted the mathematical relationship between Gini coefficient and poverty when researching poverty, income inequality, and their measurement.

Moreover, a lot of scholars studied the relationship between income inequality and income mobility by adopting various data and methods. Qi et al. [25] (2007) and other scholars discovered that the effect of the variation of income mobility on income gap becomes more obvious with the help of the survey data in Chinese rural areas. Xin and Jiyong [26] (2012) decomposed income mobility into three parts, namely, increase, dispersion, and exchange, by adopting Counterfactual Decomposition and then established the panel data model to examine the respective influential effect of the three parts on income inequality. Their conclusions were listed as follows: the gross income mobility had significant deteriorative effect on income inequality; enhancing the mobility was conducive to lower the degree of income inequality; dispersing and exchanging the mobility increased the degree of income inequality significantly. Jiandong et al. [27] (2013) and other scholars explored the relationship between income mobility and inequality on Pareto Distribution. All the research above was about the relationship between income inequality and poverty only and the relationship between income inequality and mobility only. Any literature integrating the three parts for analysis has not been found so far. In addition, most of the research above was based on empirical analysis. However, as far as the authors are concerned, the study on income inequality cannot be separated from the systematical research of the internal relationship among income inequality, income mobility, and poverty. Only in this way the pattern of residential income distribution can be studied comprehensively, adequately, and dynamically so as to provide a scientific and effective action plan about narrowing the income gap. Hence, this paper provides the theoretical and empirical research on the relationship among income inequality, income mobility, and poverty from the perspective of Distribution Function.

The paper is organized as follows. The second part is the theoretical research, in which the authors discuss the quantitative relationship among Gini coefficient, poverty ratio, and income mobility by adopting five Two-Parameter Distribution Functions as well as their Gini coefficient expressions. The third part is the empirical research, in which the authors adopt relevant data of urban residential households classified by absolute income in China City (town) Life and Price Statistics Yearbook from 2006 to 2011 and data of the nationwide average subsistence allowances as well as household average poverty population from 2005 to 2010 published by the Ministry of Civil Affairs and then compare the fitting results of different Distribution Functions on urban residential income distribution as well as the income inequality, poverty, and income mobility of urban residents. The last part is about conclusions and policy suggestions. It is important to note that as the data from Statistic Yearbook of Chinese Urban Life and Prices as well as the Ministry of Civil Affairs is measured by household, the poverty ratio and Gini coefficient in the empirical part of the paper are calculated by household as well.

\section{Theoretical Research}

According to our research, there are hundreds of Distribution Functions, in which more than 30 functions can be used to describe income distribution and less than 20 functions can 
TABle 1: Five Distribution Functions and respective expressions of Gini coefficient.

\begin{tabular}{lcc}
\hline Distribution Function & Expression & Gini coefficient \\
\hline Pareto Distribution & $F(x ; x, \alpha)=1-\left(\frac{x_{m}}{x}\right)^{\alpha}, x>0$ & $G=\frac{1}{2 \alpha-1}$ \\
\hline Log-Logistic Distribution & $F(x ; \alpha, \beta)=\frac{x^{\beta}}{x^{\beta}+\alpha^{\beta}}, x>0$ & $G=\frac{1}{\beta}$ \\
\hline Lomax Distribution & $F(x ; b, q)=1-\left(1+\frac{x}{b}\right)^{-q}, x>0$ & $G=\frac{q}{2 q-1}$ \\
\hline Weibull Distribution & $F(x ; \alpha, \beta)=1-e^{-(x / \beta)^{\alpha}}, x>0$ & $G=1-2^{-1 / \alpha}$ \\
\hline Lognormal Distribution & $F(x ; \mu, \sigma)=\Phi\left(\frac{\ln x-\mu}{\sigma}\right), x>0$ & $G=2 \Phi\left(\frac{\sigma}{\sqrt{2}}\right)-1$ \\
\hline
\end{tabular}

be used to get the expression of Gini coefficient (or other index on income inequality) directly. Moreover, the functions can be classified into Two-Parameter Distribution Functions and Multiparameter Distribution Functions based on the amount of the parameters. Parameters of Multiparameter Distribution Functions appear to be more complex than those of Two-Parameter Distribution Functions. In addition, after comparing the fitting results of nine Distribution Functions and three nonparameter estimation methods, Mengxu et al. [28] (2013) and other scholars reached the conclusion that parametric methods are obviously better than nonparametric methods for nonparametric methods hamper the fitting results due to information redundancy provided that the right-skewed and smooth unimodal distribution like income distribution is analyzed. Therefore, the five most frequently used Two-Parameter Distribution Functions are adopted for discussion in this paper.

(1) Cumulative Distribution Function (CDF) and Gini Coefficient of the Five Distribution Functions. The distribution of random variables can be described according to the probability density functions (PDF) or CDFs. Table 1 listed the respective CDF and expressions of Gini coefficient of five frequently used Distribution Functions.

In Pareto Distribution, the morphological parameter $\alpha$ is used to measure the thickness of the right tail, and the scale parameter $x_{m}$ is decisive to the range of the distribution. Table 1 shows that the Gini coefficient of Pareto Distribution is related only to the morphological parameter $\alpha$; namely, the larger $\alpha$ the smaller Gini coefficient. Pareto [4] (1895) considered that all the income distributions are subjected to Pareto Distribution, but, according to some empirical research, scholars nowadays have found that Pareto Distribution can only apply to the income distribution of $1 \%$ to $3 \%$ of the highest income groups rather than perfectly fit the distributions of every income group (Lydall [29] 1968; Harrison [19] 1981).

Log-Logistic Distribution or Fisk Distribution has abovezero scale parameter $\alpha$ (median) and morphological parameter $\beta$. The expression of Gini coefficient based on LogLogistic Distribution is very simple, namely, the reciprocal of $\beta$. According to the research on the agricultural income in England and Welsh from 1955 to 1956 as well as American residential income in 1954, Fisk [18] (1961) found that the fitting result of Log-Logistic Distribution worked well.

Lomax Distribution is often known as Pareto SecondSpecies Distribution (Arnold [17], 1983) with the morphological parameter $q$ and the scale parameter $b$. In the expression of Gini coefficient, $q>1$ results in Gini coefficient greater than 0.5 . It is obvious that this function is appropriate for the groups with the wide income gap.

In Weibull Distribution, both the morphological parameter $\alpha$ and the scale parameter $\beta$ are greater than zero. Just as the Two-Parameter Distribution Functions above, the Gini coefficient on Weibull Distribution is related only to the morphological parameter $\alpha$; namely, the larger $\alpha$ the smaller Gini coefficient. According to McDonald's [10] (1984) research, the fitting result of Weibull Distribution is better than that of other two Two-Parameter Distribution Functions.

Lognormal Distribution, or Galton Distribution, was proposed by Gibrat [30] (1931) firstly. It means that if $Y=$ $\log (X)$ is subjected to normal distribution, the $X$ will be subjected to Lognormal Distribution. $\mu$ and $\sigma$ are the mean value and standard deviation, respectively, of the variable natural logarithm.

(2) Relationship between Income Inequality and Poverty. Provided that the Income Distribution Function is given, we can deduct the relationship between poverty ratio and income inequality. For instance, say the poverty line is $L$ on Pareto Distribution Function, the expression of poverty ratio is $P_{\text {pov }}=\operatorname{Pr}(X \leq L)=F\left(L ; x_{m}, \alpha\right)=1-\left(x_{m} / L\right)^{\alpha}$. Hence, according to the expression of Gini coefficient in Table 1, it can be concluded that $\alpha=(1 / 2 G)+(1 / 2)$. So $P_{\text {pov }}=1-$ $\left(x_{m} / L\right)^{(1 / 2 G)+(1 / 2)}$.

Provided that the income distribution is subjected to Lognormal Distribution and the poverty line is $L$, it can be deducted that $P_{\text {pov }}=\operatorname{Pr}(X \leq L)=F(L ; u, \sigma)=\Phi((\ln L-$ $\mu) / \sigma)$. As $G=2 \Phi(\sigma / \sqrt{2})-1$ is given, thus $\sigma=\sqrt{2} \Phi^{-1}((G+$ 1)/2) and $P_{\mathrm{pov}}=\Phi\left((\ln L-\mu) / \sqrt{2} \Phi^{-1}((G+1) / 2)\right)$.

Similarly, we can deduct the relationships between poverty ratio and Gini coefficient on Log-Logistic Distribution, Lomax Distribution, and Weibull Distribution, respectively. The results are listed in Table 2. 
TABLe 2: Poverty ratio of the five Distribution Functions.

\begin{tabular}{lc}
\hline Distribution Function & Expression of poverty ratio \\
\hline Pareto Distribution & $P_{\text {pov }}=1-\left(\frac{x_{m}}{L}\right)^{1 / 2 G+1 / 2}$ \\
\hline Log-Logistic Distribution & $P_{\text {pov }}=\frac{1}{1+(\alpha / L)^{1 / G}}$ \\
\hline Lomax Distribution & $P_{\text {pov }}=1-\left(1+\frac{L}{b}\right)^{G /(1-2 G)}$ \\
\hline Weibull Distribution & $P_{\text {pov }}=1-e^{-(L / \beta)^{-\ln (2 /(1-G))}}$ \\
\hline Lognormal Distribution & $P_{\text {pov }}=\Phi\left(\frac{\ln L-\mu}{\sqrt{2} \Phi^{-1}((G+1) / 2)}\right)$ \\
\hline
\end{tabular}

According to Table 2, we can find the relationships between income inequality and poverty ratio on different income distributions. For instance, here is a chart of the relationship between Gini coefficient and poverty ratio on Log-Logistic Distribution (see Figure 1).

In Figure 1, every right-leaning curve represents the relationship between Gini coefficient and poverty ratio when the ratio of median $\alpha$ to the poverty line $L$ stays the same. It is very obvious that $\alpha>L, \partial P / \partial G>0 ; \alpha<L, \partial P / \partial G<0$.

According to the expression of poverty ration in Table 2, we can deduct the partial derivative of poverty ratio to Gini coefficient, namely, the sensitivity of poverty ratio to Gini coefficient. Consider

$$
\frac{\partial P_{\mathrm{pov}}}{\partial G}=\frac{1}{\left[1+(\alpha / L)^{1 / G}\right]^{2} G^{2}}\left(\frac{\alpha}{L}\right)^{1 / G} \ln \left(\frac{\alpha}{L}\right) .
$$

It is quite clear that the value on the right side of the equation is greater than zero; that is, the directions of the change of both poverty ratio and Gini coefficient are the same. Generally, the greater the income inequality is, the higher the poverty ratio is. However, the impact of income inequality on poverty ratio depends on the median to poverty line ratio. If the value of $\alpha / L$ becomes greater, namely, the income median is much higher than poverty line, the curve tends to protrude into the upper left and the poverty ratio is lower; if the value of $\alpha / L$ becomes smaller, namely, the income median is close to poverty line, the curve tends to protrude into the lower right and the poverty ratio is higher.

(3) Relationship between Income Inequality and Income Mobility. As we know, the Gini coefficient of a certain year cannot reflect the long-term income inequality. For instance, in an economy containing only two people, the first year income distribution is $(1,0)$ and the second year income distribution is $(0,1)$. Thus, the value of Gini coefficient remains 1 every year, meaning that the income distribution is extremely unequal. However, the per capita income remains 1 in the two years, meaning that the income distribution is absolutely equal. It is because Gini coefficient is a static gap index calculated from the cross-section data of income, thus it can only reflect the income distribution at a certain time point rather than the dynamic change of the sequence of individual income in income distribution. Hongliang et al. [31] (2012) and other scholars pointed out that what we should worry

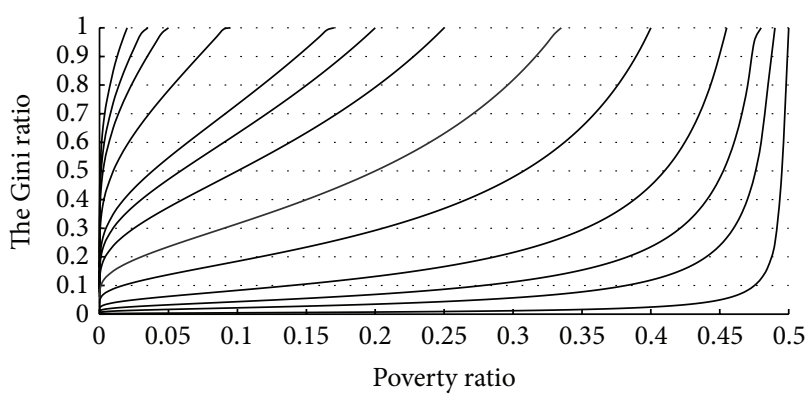

Figure 1: Relationship between Gini coefficient and poverty ratio.

about most was not income inequality and its growth but the halt of income mobility.

Therefore, in order to research income inequality more thoroughly, we researched the relationship between income mobility and income inequality. Income mobility refers to the change of relative position or the sequence of residential income in society. High mobility represents a changeful position in income distribution. Currently, the frequently used analysis tools for income mobility include Income Transition Matrix, Shorrocks Mobility Index (Shorrocks [32], 1978), and Average Mobility Index (Bartholomew [33], 1982). In this paper, the authors adopt the method proposed by Ebert [34] (1984) to study the internal relationship among income mobility, income inequality, and poverty ratio for this method can integrate income mobility, income inequality, and poverty ratio by means of Income Distribution Function. Consider

$$
d^{r}(X, Y)=\left(\int_{0}^{1}\left|F_{X}^{-1}(v)-F_{Y}^{-1}(v)\right|^{r} d v\right)^{1 / r}, \quad r \geq 1 .
$$

In Formula (2), $F_{X}^{-1}$ and $F_{Y}^{-1}$ are inverse functions of residential income $\mathrm{CDFs}$ in different periods, respectively. If $r$ is 1, Formula (2) becomes

$$
d(X, Y)=\int_{0}^{1}\left|F_{X}^{-1}(v)-F_{Y}^{-1}(v)\right| d v .
$$

Provided that the income of a group is subjected to Pareto Distribution in early and last phases, $x_{m}^{0} G_{0}$ and $x_{m}^{1} G_{1}$ represent the minimum $x$ and Gini coefficient in early and last phase, respectively, and parameter $\alpha$ is replaced by Gini coefficient; then the CDF becomes $F(x)=1-\left(x_{m} / x\right)^{(1 / G+1) / 2}$. Hence, $F^{-1}(v)=x_{m} /(1-v)^{2 G /(G+1)}$, and the relationship between Gini coefficient and income mobility on Pareto Distribution is

$$
d(X, Y)=\int_{0}^{1}\left|\frac{x_{m}^{1}}{(1-v)^{2 G_{1} /\left(1+G_{1}\right)}}-\frac{x_{m}^{0}}{(1-v)^{2 G_{0} /\left(1+G_{0}\right)}}\right| d v .
$$

Obviously, income mobility is closely related to Gini coefficients in early and last phases. Similarly, we can get CDFs containing Gini coefficient on Log-Logistic Distribution, Lomax Distribution, and Weibull Distribution and then 
TABLE 3: Income mobility of the five Distribution Functions.

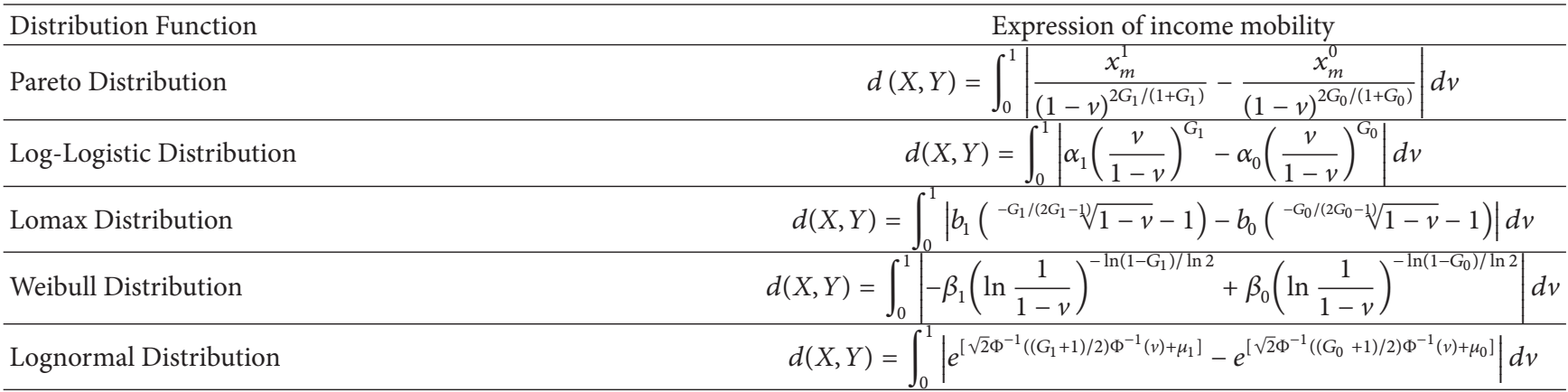

TABLE 4: Relationships between poverty ration and income mobility of the five Distribution Functions.

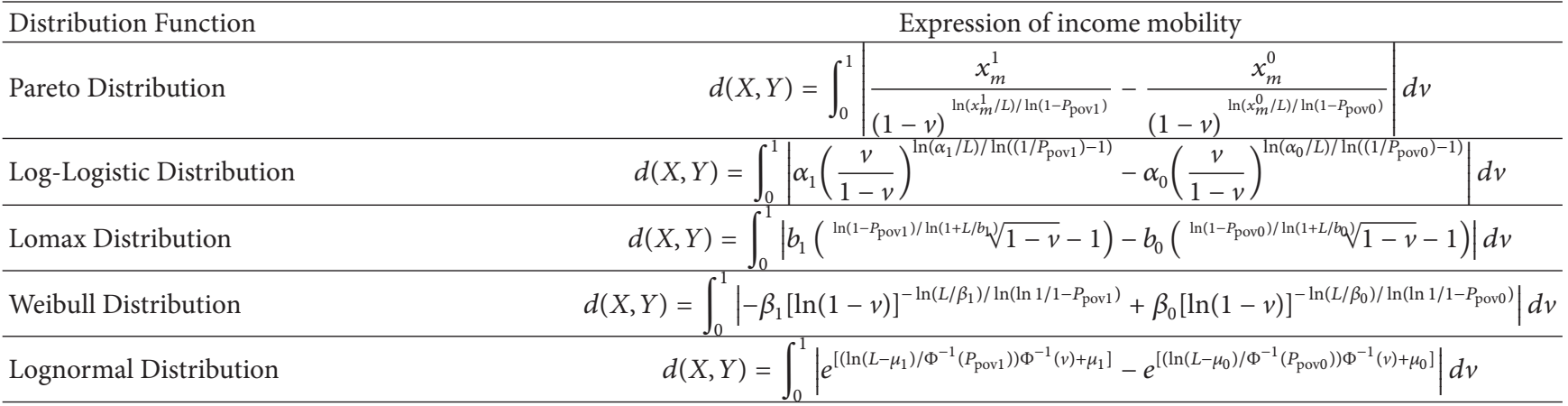

deduct the quantitative relationships between Gini coefficient and income mobility of the Distribution Functions above.

(4) Relationship between Poverty Ratio and Income Mobility. When being given the Distribution Function, we can find the relationship between poverty ratio and income mobility by putting the expression of Gini coefficient containing poverty ratio into the formula of income mobility. Take Log-Logistic Distribution for instance. From Table 2, $P_{\text {pov }}=1 /(1+$ $\left.(\alpha / L)^{1 / G}\right)$, so $G=\ln (\alpha / L) / \ln \left(\left(1 / P_{\text {pov }}\right)-1\right)$. When putting the formula into the expression of income mobility in Table 3 , we can find

$$
\begin{aligned}
d(X, Y)=\int_{0}^{1} \mid \alpha_{1} & \left(\frac{v}{1-v}\right)^{\ln \left(\alpha_{1} / L\right) / \ln \left(\left(1 / P_{\mathrm{pov} 1}\right)-1\right)} \\
& -\alpha_{0}\left(\frac{v}{1-v}\right)^{\ln \left(\alpha_{0} / L\right) / \ln \left(\left(1 / P_{\mathrm{pov} 0}\right)-1\right)} \mid d v .
\end{aligned}
$$

Based on Tables 2 and 3, the relational expressions of poverty ratio and income mobility of the Distribution Functions above are listed in Table 4.

\section{Empirical Studies}

(1) Fitting of Distribution Function of Income of Urban Residents. Based on the above research results, we will further discuss the income inequity, impoverishment rate, and income mobility of urban residents in China. According to a number of research results, Pareto Distribution Function is limitedly applied in high-income groups and, instead, it is poorly fitted in the entire income distribution. For example, Lydall [29] (1968) concluded that Pareto Distribution was merely applied in the $15 \%-20 \%$ highest income groups through observing the income distribution of male employees in private enterprises in various developing countries. Harrison [19] (1981) further verified, based on the income data in Britain, that the function was only fitted with $20 \%$ highest income groups. In addition, as previously mentioned, the morphological parameter of Lomax Distribution is $q>1$ and, therefore, the Gini coefficient is greater than 0.5 , which shows that it is limitedly applied in the extreme income inequality. However, according to researches of many scholars (such as Chen and Daidai [35], 2011; Chuliang and Yake [36], 2012; Research Group of Social Development Institute of NDRC [37], 2012; Mengxu et al. [28], 2013), the Gini coefficient of urban residents' income in China has not yet reached 0.4. Consequently, we abandoned Pareto Distribution and Lomax Distribution and applied Log-Logistic, Weibull, and Lognormal functions to in fitting the income distribution of urban residents in China. The fitting results of MATLAB can be referred to in Table 5. When fitting practical income distribution, generally, the fitting error of both ends of the income distribution is relatively bigger. As this paper is directed toward studying poverty in urban areas with all poor families gaining less than 10-thousand-yuan revenue, we pay special attention to the fitting results of relevant Distribution Functions on urban families with less than 10thousand-yuan revenue. This research adopted the income and population data of 20 groups of urban families divided 
TABle 5: Parameter evaluation and goodness of fittest of three Distribution Functions.

\begin{tabular}{|c|c|c|c|c|c|c|}
\hline Lognormal & $\mu$ & $\sigma$ & Theoretical $\operatorname{Pr}(X<10000)$ & Actual $\operatorname{Pr}(X<10000)$ & $\Delta \operatorname{Pr}=(2)-(1)$ & Chi-square value \\
\hline 2005 & 10.2317 & 0.6050 & 0.0457 & 0.0485 & 0.0029 & 203 \\
\hline 2006 & 10.3418 & 0.5975 & 0.0291 & 0.0325 & 0.0034 & 252 \\
\hline 2007 & 10.4867 & 0.5954 & 0.0160 & 0.0209 & 0.0049 & 273 \\
\hline 2008 & 10.6275 & 0.6164 & 0.0108 & 0.0148 & 0.0041 & 258 \\
\hline 2009 & 10.7312 & 0.6022 & 0.0058 & 0.0088 & 0.0030 & 220 \\
\hline 2010 & 10.8300 & 0.6014 & 0.0035 & 0.0068 & 0.0033 & 466 \\
\hline Log-Logistic & $\alpha$ & $\beta$ & Theoretical $\operatorname{Pr}(X<10000)$ & (2) Actual $\operatorname{Pr}(X<10000)$ & $\Delta \operatorname{Pr}=(2)-(1)$ & Chi-square value \\
\hline 2005 & 27753 & 2.8731 & 0.0506 & 0.0485 & -0.0021 & 101 \\
\hline 2006 & 30973 & 2.9147 & 0.0357 & 0.0325 & -0.0032 & 100 \\
\hline 2007 & 35950 & 2.9256 & 0.0231 & 0.0209 & -0.0022 & 90 \\
\hline 2008 & 41488 & 2.8115 & 0.0180 & 0.0148 & -0.0032 & 128 \\
\hline 2009 & 46017 & 2.8712 & 0.0123 & 0.0088 & -0.0035 & 177 \\
\hline 2010 & 51002 & 2.8978 & 0.0088 & 0.0068 & -0.0020 & 110 \\
\hline Weibull & $\alpha$ & $\beta$ & Theoretical $\operatorname{Pr}(X<1000)$ & (2) Actual $\operatorname{Pr}(X<1000)$ & $\Delta \operatorname{Pr}=(2)-(1)$ & Chi-square value \\
\hline 2005 & 1.5924 & 37296 & 0.0157 & 0.0485 & 0.0328 & 6603 \\
\hline 2006 & 1.6485 & 41295 & 0.0920 & 0.0325 & -0.0595 & 6657 \\
\hline 2007 & 1.7350 & 47333 & 0.0652 & 0.0209 & -0.0443 & 5721 \\
\hline 2008 & 1.7678 & 54349 & 0.0489 & 0.0148 & -0.0341 & 4666 \\
\hline 2009 & 1.8543 & 59448 & 0.0360 & 0.0088 & -0.0272 & 4157 \\
\hline 2010 & 1.9338 & 65093 & 0.0264 & 0.0068 & -0.0196 & 3394 \\
\hline
\end{tabular}

Note. The theoretical $\operatorname{Pr}(X<10000)$ is proportion of families with the annual income less than 10 thousand yuans in the total households, which is calculated in line with relative Distribution Function; the actual $\operatorname{Pr}(X<10000)$ is the proportion of urban families with annual income less than 10 thousand yuans in the total urban households in reality. The data is from China City (town) Life and Price Statistics Yearbook.

by absolute income, which was from China City (town) Life and Price Statistics Yearbook from 2006 to 2011. The data was more detailed compared with that of seven groups in China Statistical Yearbook.

The level of the goodness of fittest depends on the chisquare value, which reflects the degree of deviation between actual observations and theoretical estimations. The smaller the number is, the lower degree of deviation is and the higher goodness of fittest is. From Table 5, it was seen that the chi-square value of Log-Logistic Distribution from 2005 to 2010 was between 90 and 177 , which was much smaller than the other two Distribution Functions. It reflected that this distribution had achieved the highest overall best of fittest for income distribution of urban residents; Lognormal Distribution ranked in the second place and Weibull Distribution achieved worst results, whose chi-square value was maintained above 3000 historically and even achieved 6657 in 2006. However, for urban households with annual income less than 10 thousand yuan, Log-Logistic Distribution achieved highest best of fittest. From 2005 to 2010, for LogLogistic Distribution, the difference of actual proportion and theoretical values of urban households in the total households, known as $\Delta \mathrm{Pr}$, with its maximum absolute value being 0.0035 and the minimum being 0.002 , reflected that it slightly overestimated the proportion of urban households as the numbers were negative. Similar to the entire effectiveness, the best of fittest of Lognormal Distribution for low-income groups was slightly lower than that of Log-Logistic Distribution, with its absolute value being between 0.0029 and 0.0049 .
As numbers were positive, it underestimated the proportion of urban families with annual income less than 10 thousand yuan. The worst effect still belonged to Weibull Distribution, whose maximum absolute value hit 0.0595 and minimum reached as high as 0.0196 .

Therefore, for both of urban households with annual income less than 10 thousand and all urban residents, they could be well fitted by the Log-Logistic Distribution. Here, we have made a table of income distribution of urban residents from 2005 to 2010 based on Log-Logistic Distribution (see Figure 2), and Tables 6, 7, 9, and 10 are also based on the LogLogistic Distribution.

(2) Relationship between Income Inequity and Poverty of Urban Residents from 2005 to 2010. After having an idea of income distribution of urban residents in China, the next step is to conduct empirical analysis of the tie between urban Gini coefficient and poverty ratio from 2005 to 2010. For the calculation results, as shown in Table $6, \alpha$ refers to income median. $\beta$, as the morphological parameter, is the reciprocal to $G$, the Gini coefficient. $L$ means poverty standard while $P_{\text {pov }}$ is the poverty ratio.

Apparently, the poverty ratio of $2005-2010$ is maintained relatively low, between $0.88 \%$ and $1.41 \%$ (refer to Table 6), as we calculated poverty ratio based on income data including the national minimum living standard assistance for urban poor families, without which the rate would rise surely. According to Table 6, from 2005-2007, with the annual increase of median, $\alpha$, and poverty standard, $L$, both 


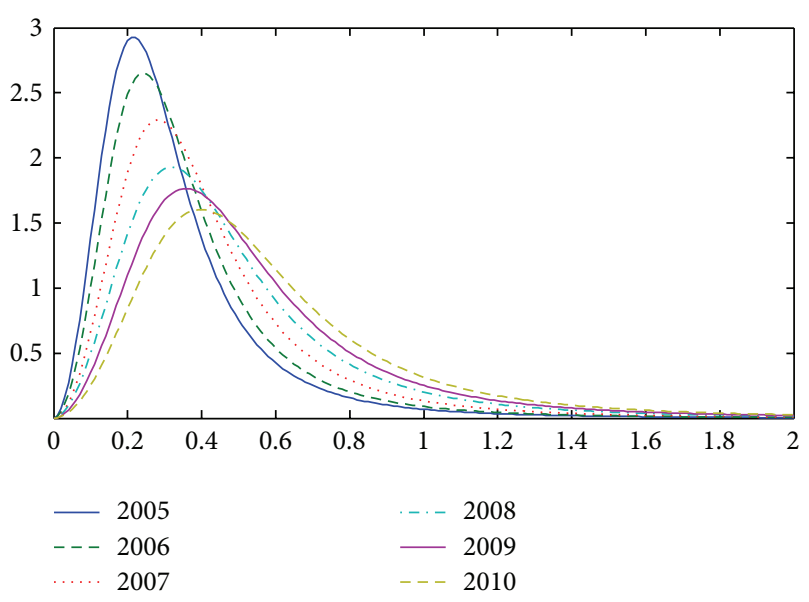

FIGURE 2: Income distribution of urban residents from 2005 to 2010. Note that the revenue unit is 100 thousand.

poverty ratio and Gini coefficient show a downward trend, respectively, from $1.41 \%$ and 0.3481 to $0.94 \%$ and 0.3418 . Compared to 2007, both figures increased, and poverty ratio and Gini coefficient increased by $7.45 \%$ and $4.07 \%$. Since then, the poverty ratio had decreased by $12.87 \%$ in 2010 , and the Gini coefficient had declined by $3 \%$. To further discuss the relationship between two sides, we, taking the poverty lines of the year 2005 and 2010 as the standard, discuss the changing situation of various median $\alpha$ and Gini coefficient $G$ (see Table 7).

The median, $\alpha$, reflects the changes of income and the Gini coefficient, $G$, shows the change of income distribution. Both of changes would exert a direct influence on the changes in poverty ratio. In Table 7 , standard 1 is set in line with the poverty line, income median, and Gini coefficient in 2005. Based on the standard 1 and situation 2, we could find that when $\alpha$ was constant, the direction of poverty ratio was in line with Gini coefficient. Compared with standard 1, when $\alpha$ increased from 27753 to 44525 and $G$ was constant, the poverty ratio greatly decreased (situation 3 ). According to data in situation 4, when $\alpha$ increased and $G$ decreased, the poverty ratio further declined. For standard 2 , except increased poverty line, other conditions are the same as standard 1. Compared to standard 2, when median $\alpha$ was constant while $G$ decreased, the poverty ratio slightly dropped (situation 6). As the situation 7 and 8 showed, when $\alpha$ increased while $G$ stayed unchanged or declined, the poverty ratio would decrease dramatically.

The above analysis indicated that when, $\alpha / L$, the ratio of the median and the poverty line rose, meanwhile, the Gini coefficient was fixed and the poverty ratio would go down definitely, and vice versa. Only when $\alpha / L$ stayed constant, the poverty ratio would change in line with the Gini coefficient. The larger the Gini coefficient was, the higher the poverty ratio would be, which was consistent with the conclusion of theoretical researches.

For the former empirical analysis, we applied the urban income data including low-income part. To further expound
TABLE 6: Gini coefficient and poverty ratio of urban residents from 2005 to 2010.

\begin{tabular}{cccccc}
\hline Year & $\alpha$ & $\beta$ & $L$ (yuan/year) & $P_{\text {pov }}(\%)$ & $G$ \\
\hline 2005 & 27753 & 2.8731 & 6327.36 & 1.41 & 0.3481 \\
2006 & 30973 & 2.9147 & 6716.16 & 1.15 & 0.3431 \\
2007 & 35950 & 2.9256 & 7310.59 & 0.94 & 0.3418 \\
2008 & 41488 & 2.8115 & 8129.88 & 1.01 & 0.3557 \\
2009 & 46017 & 2.8712 & 9102.88 & 0.94 & 0.3483 \\
2010 & 51002 & 2.8978 & 10007.81 & 0.88 & 0.3451 \\
\hline
\end{tabular}

Note. $L$, the poverty standard, is calculated according to 2005-2010 National Average Minimum Standard for Urban Residents and Average Poverty Population in each family. The formula is as follows: poverty standard $($ yuan $/$ year $)=$ minimum urban standards $($ yuan $/$ month $) \times 12$ (month). The poverty ratio is calculated based on Table 2 .

this situation, we listed the income of poor groups and subsistence allowances in urban areas.

Generally speaking, groups with higher income, compared with relatively lower income, enjoyed a faster increase of income. However, according to the last line of Table 8, the per capita income of urban residents in 2010 was 1.8212 times as big as that in 2005 , while the per capita income of $5 \%$ of the lowest income groups in urban areas was nearly 1.9 times as big as that in 2005, which indicated a faster growth rate of annual income of urban residents. It was justified that $5 \%$ of the lowest income groups enjoyed the subsistence allowances, without which it was estimated that the per capita annual income in 2010 was just 1.5079 times higher than that in 2005. It showed that China's assistance allowances had played a significant role in reduction of poverty ratio, which well explained the reason why the poverty ratio was lower when the allowances were included as well.

(3) The Relationship of Urban Income Inequality and Income Mobility from 2005 to 2010. Based on the formula of LogLogistic Distribution for income mobility, we calculated income mobility in different base periods and reporting periods (as seen in Table 9). In Table 9, the diagonal data reflected the fluctuations of annual income mobility. In addition to the fact that it dropped, compared with that of the period of 2008-2009, the income fluidity of other periods rose.

More importantly, the full table showed that the longterm mobility was greater than short-term one. Taking the first line of 2005 as the base period, the income mobility was increased from 3170 in 2005-2006 period to 7238 in 20052007 period and finally reached 20446 in the period of 20052010. Another example was the last line of the reporting period of 2010. The income mobility of the year 2005, as the base period, was larger than that in 2006, 2007, and 2008 as well as 2009.

However, the above data failed to reflect whether the income equality accelerated or slowed down. Shorrocks [32] (1978), Atkinson et al. [38] (1992), and Jarvis and Jenkins [39] (1998) promoted that notion that income mobility functions as an equalizer of long-term distribution. Fields 
TABLE 7: Urban poverty ratio in different situation.

\begin{tabular}{|c|c|c|c|c|c|c|}
\hline Circumstance & Circumstance & $L$ (yuan/year) & $\alpha$ & $\beta$ & $P_{\mathrm{pov}}(\%)$ & G \\
\hline 1 & Standard 1 & 6327.36 & 27753 & 2.8731 & 1.41 & 0.3481 \\
\hline 2 & $G \downarrow$ & 6327.36 & 27753 & 2.8978 & 1.36 & 0.3451 \\
\hline 3 & $\alpha \uparrow(\alpha / L \uparrow)$ & 6327.36 & 44525 & 2.8731 & 0.37 & 0.3481 \\
\hline 4 & $\alpha \uparrow(\alpha / L \uparrow), G \downarrow$ & 6327.36 & 44525 & 2.8978 & 0.35 & 0.3451 \\
\hline 5 & Standard 2 & 8736.63 & 27753 & 2.8731 & 3.49 & 0.3481 \\
\hline 6 & $G \downarrow$ & 8736.63 & 27753 & 2.8978 & 3.39 & 0.3451 \\
\hline 7 & $\alpha \uparrow(\alpha / L \uparrow)$ & 8736.63 & 44525 & 2.8731 & 0.92 & 0.3481 \\
\hline 8 & $\alpha \uparrow(\alpha / L \uparrow), G \downarrow$ & 8736.63 & 44525 & 2.8978 & 0.88 & 0.3451 \\
\hline
\end{tabular}

Note. (1) $\alpha=27753$ was the median of urban income in 2005 , and $\alpha=44525$ was the median of urban income for 2010 calculated by 2005 urban consumer prices index. (2) For the first to fourth circumstance, it applied the poverty line of $2005,6327.36$ yuan, and the fifth to eighth circumstances applied the poverty line of 2010, 8736.63 yuan. (3) The actual poverty line = current poverty line/urban consumer price index. (4) $G=0.3481$ was the Gini coefficient of 2005, while $G=0.3451$ was the Gini coefficient of 2010. (5) “ $\uparrow$ " (up) and “ $\downarrow$ ” (down) in the table represented the direction of change.

TABLE 8: Income and subsistence allowance of poor groups in urban areas from 2005 to 2010.

\begin{tabular}{|c|c|c|c|c|c|}
\hline Year & $\begin{array}{l}\text { Per capita annual } \\
\text { income of urban } \\
\text { residents } \\
\text { (yuan) }\end{array}$ & $\begin{array}{c}\text { Per capita annual } \\
\text { income of } 5 \% \text { of the } \\
\text { lowest income groups } \\
\text { in urban areas } \\
\text { (yuan) }\end{array}$ & $\begin{array}{c}\text { The number of urban } \\
\text { people receiving } \\
\text { subsistence } \\
\text { allowances (ten } \\
\text { thousand people) }\end{array}$ & $\begin{array}{c}\text { Expenses of } \\
\text { households receiving } \\
\text { subsistence } \\
\text { allowances } \\
\text { (ten thousand yuan) }\end{array}$ & $\begin{array}{l}\text { Per capita expenses of } \\
\text { households receiving } \\
\text { subsistence } \\
\text { allowances } \\
\text { (yuan) }\end{array}$ \\
\hline 2005 & 10493.03 & 2495.75 & 2234.2 & 191.9 & 858.92 \\
\hline 2006 & 11759.45 & 2838.87 & 2240.1 & 224.2 & 1000.85 \\
\hline 2007 & 13785.81 & 3357.91 & 2272.1 & 277.4 & 1220.90 \\
\hline 2008 & 15780.76 & 3734.35 & 2334.8 & 393.4 & 1684.94 \\
\hline 2009 & 17174.56 & 4197.58 & 2345.6 & 482.1 & 2055.34 \\
\hline 2010 & 19109.44 & 4739.15 & 2310.5 & 524.7 & 2270.94 \\
\hline $2010 / 2005$ & 1.8212 & 1.8989 & 1.0342 & 2.7342 & 2.6439 \\
\hline
\end{tabular}

Note: the above data is from 2006-2011 China Statistical Yearbook and Statistical Bulletin of Development of Civil Affairs issued by Ministry of Civil Affairs.

TABLE 9: Income mobility of urban residents in different periods from 2005 to 2010 .

\begin{tabular}{lccccc}
\hline \multirow{2}{*}{ Base period } & \multicolumn{5}{c}{ Reporting period } \\
& 2006 & 2007 & 2008 & 2009 & 2010 \\
\hline 2005 & 3170 & 7238 & 11875 & 16885 & 20446 \\
2006 & 0 & 4068 & 8705 & 13715 & 17276 \\
2007 & 0 & 0 & 4637 & 9647 & 13208 \\
2008 & 0 & 0 & 0 & 5011 & 8571 \\
2009 & 0 & 0 & 0 & 0 & 3561 \\
\hline
\end{tabular}

[40] (1992), based on the researches conducted by Shorrocks [32] (1978) and Chakravarty et al. [41] (1985), defined the progressivity as an indicator of long-term distribution equalizer, which is short for $P$ index. Consider

$$
P=1-\frac{G(\bar{X})}{G\left(X^{\prime}\right)} .
$$

Of the function, $\bar{X}$ refers to the average income of the sequence of base period and reporting period, $X^{\prime}$ means income distribution sequence of the base period, and $G(\cdot)$ is Gini coefficient. Contrary to it, $P>0$ means the longterm income distribution is less fair than that calculated by the single year. We can use the $P$ indexto compare the role of income mobility in two periods in slowing down the income inequity. For instance, there are two periods, respectively, from $I$ to $j$ and $k$ to $l$, in addition to $P_{i j}>$ $P_{k l}$; the income mobility of the period from $I$ to $j$ plays a more important role in income equity than that of the period from $k$ to $l$. According to the evaluation of parameters $\alpha$ and $\beta$ of Log-Logistic Distribution in Table 5, we, with MATLAB, generated 6 groups ( 6 years) of random numbers and each group contains 10000 numbers representing the income revenue of urban residents in that year. With numbers ranking from low to high, we select base period and reporting period to calculate the mean of the two periods, $\bar{X}$. Finally, based on formula (6), calculate the $P$ index of urban income mobility in different periods (as seen in Table 10).

Table 10 showed that $P$ index of base period of 2006 and reporting period of 2008 was less than 0 , which meant that, during these periods, income distribution calculated by the single year was fair compared to the long-term income distribution and income mobility which accelerated instead of slowing down. By observing the Gini coefficient, we could find that, from 2005 to 2010, the Gini coefficient reflected the dropping-rocketing-dropping process. In 2007, it reached its minimum and slightly increased in 2006 while the year 2008 marked the maximum of the Gini coefficient. Therefore, 
TABle 10: $P$ index of income mobility of urban residents in different periods from 2005 to 2010 .

\begin{tabular}{lccccc}
\hline \multirow{2}{*}{ Base period } & \multicolumn{5}{c}{ Reporting period } \\
& 2006 & 2007 & 2008 & 2009 & 2010 \\
\hline 2005 & 0.0095 & 0.0072 & -0.0184 & 0.0012 & 0.0078 \\
2006 & - & -0.0032 & -0.0290 & -0.0100 & -0.0038 \\
2007 & - & - & -0.0236 & -0.0061 & -0.0003 \\
2008 & - & - & - & 0.0165 & 0.0223 \\
2009 & - & - & - & - & 0.0055 \\
\hline
\end{tabular}

it is easy to understand why $P$ index was negative in those periods. In other periods, $P$ index was greater than 0 , which showed that the long-term distribution was more fair than that calculated by single year. In addition, it was concluded by observing the calculation results in each row and each column, within the same base period or reporting period; it was unsure that the income mobility had positive or negative impact on income inequality. Comprehensively, although the long-term income mobility of urban residents was greater than that of short-term, its influences on income inequality both accelerated and slowed down.

\section{Conclusions and Policy Recommendations}

This paper, with five distribution expressions and expression of Gini coefficient, expresses the quantitative relationship of income inequality, poverty, and income mobility through math deduction, which has not been found in relative domestic and foreign literature. Due to the close tie of the three, discussing them separately is difficult. As removing income inequality is a systematic project, it is necessary to comprehensively consider the three combined elements.

Based on the above studies of theoretical researches, we conducted the fitting of income distribution of urban residents in China from 2005 to 2010 and found that LogLogistic Distribution achieved the best effect. Therefore, we further discussed, within the Log-Logistic Distribution, the relationship of income inequality, poverty, and income mobility of urban residents in China. Based on the studies, we recommend the following.

First, strengthen the subsistence allowances for poor groups in urban areas. According to data released by National Bureau of Statistics and the Ministry of Civil Affairs, in 2012, the personal income tax totaled 60 million yuan from urban residents while only over 6 million was used for providing urban subsistence allowances. Further strengthening subsistence allowances could greatly promote the income of urban poor groups, reduce poverty ratio, and narrow the income gap between urban residents.

Second, promote the low-income groups flow to middleand high-income groups so as to narrow the income gap between urban residents. Improving the income of lowincome groups could reduce poverty ratio and narrow income gap, and on the other hand, it could also substantially mitigate the social pressure and conflicts. However, its achievement relies on the entire supporting economic restructuring. In addition to the requirements of fair provision of public resources including education, medicine, and social security, the society is required to solve the problem of reduced income mobility resulted in by nonmarket factors when promoting the market economic development and fair competition to achieve the real goal of fair starting point and process.

\section{Conflict of Interests}

The authors declare that there is no conflict of interests regarding the publication of this paper.

\section{Acknowledgments}

The authors thank the referrer for their very helpful comments. This paper is supported by the project Income Distribution Function and Its Application in China sponsored by the National Natural Science Foundation of China (Grant no. 71473203) and the Fundamental Research Funds for the Central Universities (Project no. JBK120502).

\section{References}

[1] M. O. Lorenz, "Methods of measuring the concentration of wealth," Journal of the American Statistical Association, vol. 9, pp. 209-219, 1905.

[2] M. Zenga, "Proposta Per Un Indice Di Concentrazione Basato Sui Rapporti Fra Quantili Di Popolazione E Quantili Reddito," Giornale degli Economisti e Annali di Economia, vol. 48, pp. 301326, 1984.

[3] B. C. Arnold, C. A. Robertson, P. L. Brockett, and B. Y. Shu, "Generating ordered families of Lorenz curves by strongly unimodal distributions," Journal of Business and Economic Statistics, vol. 5, pp. 305-308, 1987.

[4] V. Pareto, "La legge della domanda," Giornale degli Economisti, vol. 10, pp. 59-68, 1895.

[5] C. Kleiber and S. Kotz, Statistical Size Distributions in Economics and Actuarial Sciences, John Wiley \& Sons, Hoboken, NJ, USA, 2003.

[6] J. Aitchison and J. Brown, The Lognormal Distribution, Cambridge University Press, Cambridge, UK, 1957.

[7] J. B. McDonald and B. Jensen, "An analysis of some properties of alternative measures of income inequality based on the gamma distribution function," Journal of the American Statistical Association, vol. 74, no. 368, pp. 856-860, 1979.

[8] A. B. Salem and T. D. Mount, "A convenient descriptive model of income distribution: the gamma density," Econometrica, vol. 42, no. 6, pp. 1115-1127, 1974.

[9] J. B. McDonald, "Some issues associated with the measurement of income inequality," Statistical Distributions in Scientific Work, vol. 6, pp. 161-179, 1981.

[10] J. B. McDonald, "Some generalized functions for the size distribution of income," Econometrica, vol. 52, pp. 647-663, 1984.

[11] C. Bhattacharjee and N. Krishnaji, "DFR and other heavy tail properties in modeling the distribution of land and some alternative measure s of inequality," in Statistics: Applications and New Directions, Indian Statistical Institute, Calcutta, India, 1985. 
[12] D. C. Cronin, "Function for size distribution of incomes: a further comment," Econometrica, vol. 47, no. 3, pp. 773-774, 1979.

[13] R. J. Butler and J. B. McDonald, "Using incomplete moments to measure inequality," Journal of Econometrics, vol. 42, no. 1, pp. 109-119, 1989.

[14] J. Sloman, Economics, Financial Time Prentice Hall Europe, London, UK, 4th edition, 2000.

[15] A. Sen, On Economic Inequality, Clarendon Press, Oxford, UK, 1997.

[16] D. Champernowne and F. Cowell, Economic Inequality and Income Distribution, Cambridge University Press, Cambridge, UK, 1998.

[17] B. C. Arnold, Pareto Distributions, International Co-operative Publishing House, Fairland, Ill, USA, 1983.

[18] R. Fisk, "Estimation of location and scale parameters in a truncated grouped sech -square distribution," Journal of the American Statistical Association, vol. 56, no. 295, pp. 692-702, 1961.

[19] J. Harrison, "Earnings by size: a tale of two distributions," Review of Economic Studies, vol. 48, no. 4, pp. 621-631, 1981.

[20] F. Bourguignon, "The Poverty-growth-inequality Triangle," Tech. Rep., The Indian Council for Research on International Economic Relations, New Delhi, India, 2004.

[21] G. Wan and Y. Zhang, "The impacts of growth and inequality on poverty dynamics in China," Economic Research Journal, vol. 6, 2006.

[22] B. Hu, J. Lai, and B. Hu, "Economic growth, income distribution and poverty alleviation-evidence from rural china :19852003," Journal of Quantitative \& Technical Economics, no. 5, 2007.

[23] Z. Nong and L. Xubei, "Income growth, inequality and poverty - data analysis of China health and nutrition examination survey," Chinese Journal of Population Science, vol. 2, 2008.

[24] N. Takayama, "Poverty, income inequality, and their measures: professor Sen's axiomatic approach reconsidered," Econometrica, vol. 47, no. 3, pp. 747-759, 1979.

[25] Z. Qi, M. Jianwei, and H. Jikun, "Income mobility and income distribution: evidence from rural China," Economic Research Journal, vol. 11, 2007.

[26] L. Xin and C. Jiyong, "Income mobility and income inequalityan empirical research based on CHNS data," Journal of World Economy, vol. 9, 2012.

[27] C. Jiandong, L. Tao, and Z. Aifeng, "The application of income distribution function in the research of income disparity," Statistical Research, vol. 9, 2013.

[28] Z. Mengxu, C. Jiandong, and P. Ming, "The research on urban resident income distribution function," Journal of Quantitative \& Technical Economics, vol. 4, 2013.

[29] H. F. Lydall, The Structure of Earnings, Oxford University Press, London, UK, 1968.

[30] R. Gibrat, Les Inégalités Économiques, Librairie du Recueil Sirey, Paris, France, 1931.

[31] W. Hongliang, L. Zhibiao, and S. Wenhua, "Do Chinese residents enjoy equal opportunities for earning income? Based on microscopic measurement of income mobility," Journal of World Economy, no. 1, pp. 3-17, 2012 (Chinese).

[32] A. F. Shorrocks, "The measurement of mobility," Econometrica, vol. 46, no. 5, pp. 1013-1024, 1978.

[33] D. J. Bartholomew, Stochastic Models for Social Processes, Wiley, London, UK, 1982.
[34] U. Ebert, "Measures of distance between income distributions," Journal of Economic Theory, vol. 32, no. 2, pp. 266-274, 1984.

[35] J. Chen and Daidai, "Accelerate the urbanization process and improvement of residents' income inequality," Public Finance Research, no. 2, 2011.

[36] L. Chuliang and W. Yake, "Empirical analysis of the determinants for increasing income inequality in Urban China," Journal of Huazhong University of Science and TechnologySocial Science, vol. 26, no. 3, 2012.

[37] Research Group of Social Development Institute of National Development and Reform Commission(NDRC), "On the income gap of Chinese residents," Review of Economic Research, vol. 25, 2012.

[38] A. B. Atkinson, F. Bourguignon, and C. Morrisson, Empirical Studies of Earnings Mobility, Harwood Academic Publishers, Reading, Mass, USA, 1992.

[39] S. Jarvis and S. P. Jenkins, "Much income mobility is there in Britain?” Economic Journal, vol. 108, no. 447, pp. 428-443, 1998.

[40] G. S. Fields, Distribution and Development: A New Look at the Developing World, The MIT Press, Boston, Mass, USA, 2002.

[41] S. R. Chakravarty, B. Dutta, and J. A. Weymark, "Ethical indices of income mobility," Social Choice and Welfare, vol. 2, no. 1, pp. $1-21,1985$. 


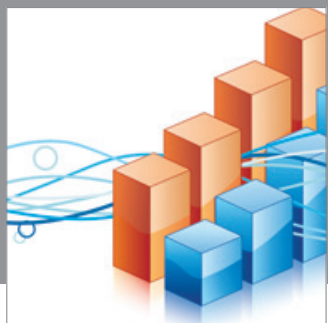

Advances in

Operations Research

mansans

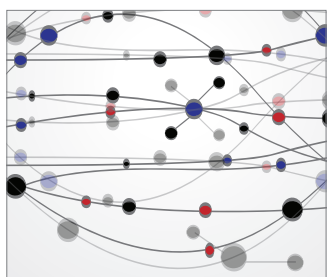

The Scientific World Journal
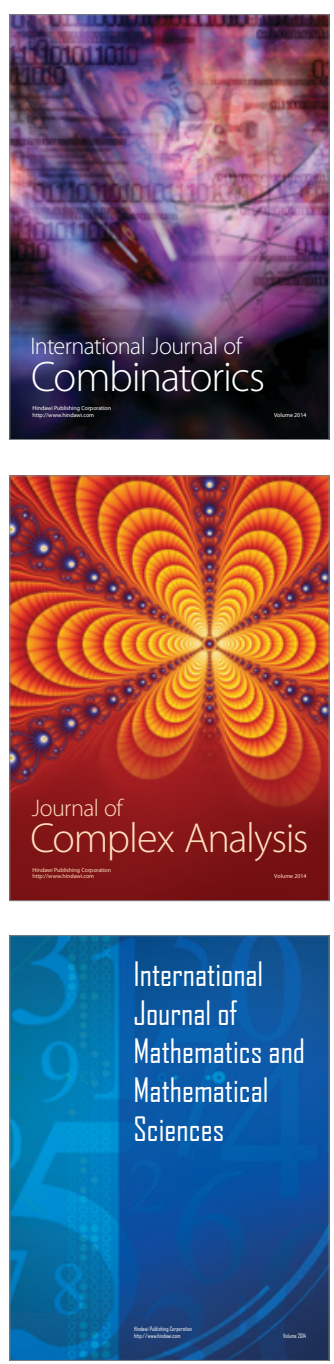
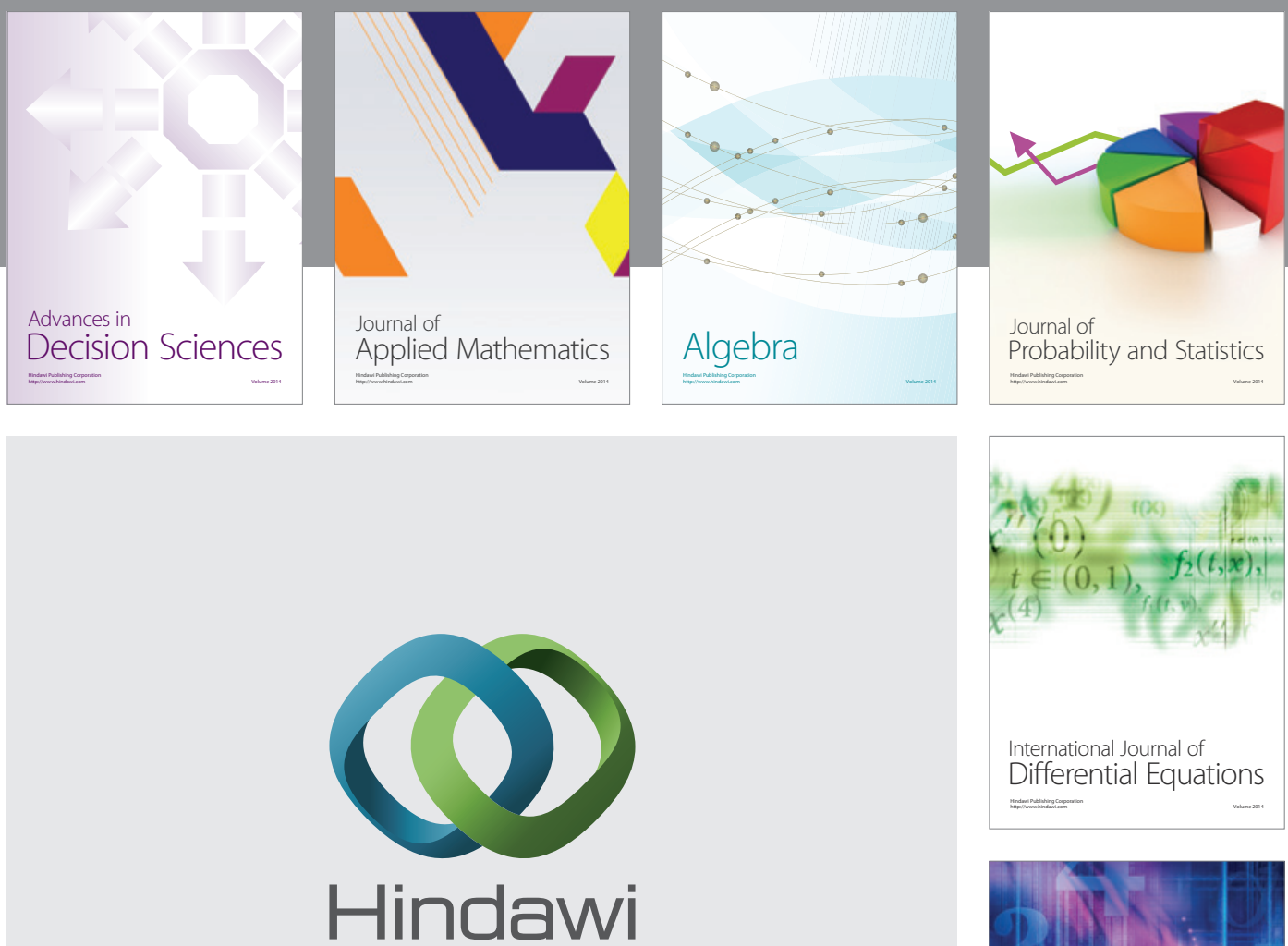

Submit your manuscripts at http://www.hindawi.com
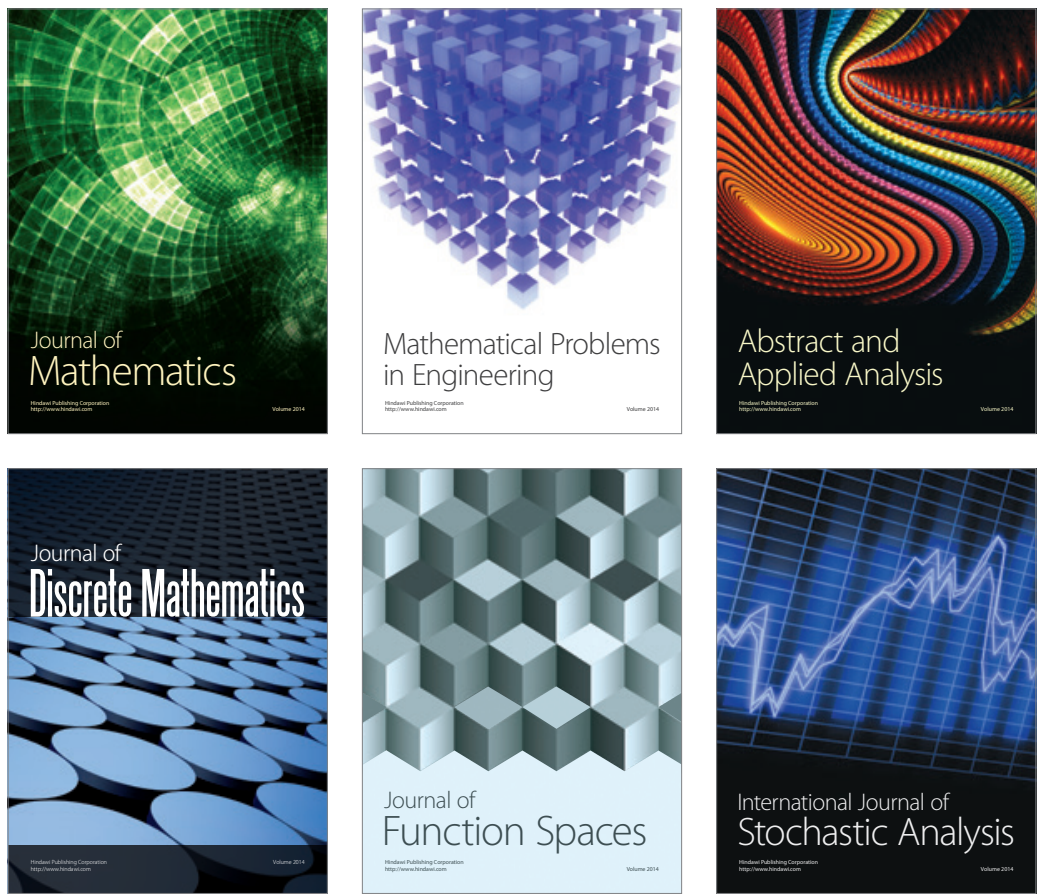

Journal of

Function Spaces

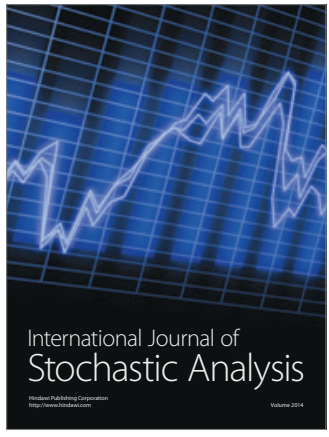

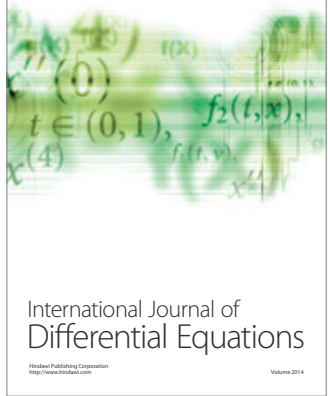
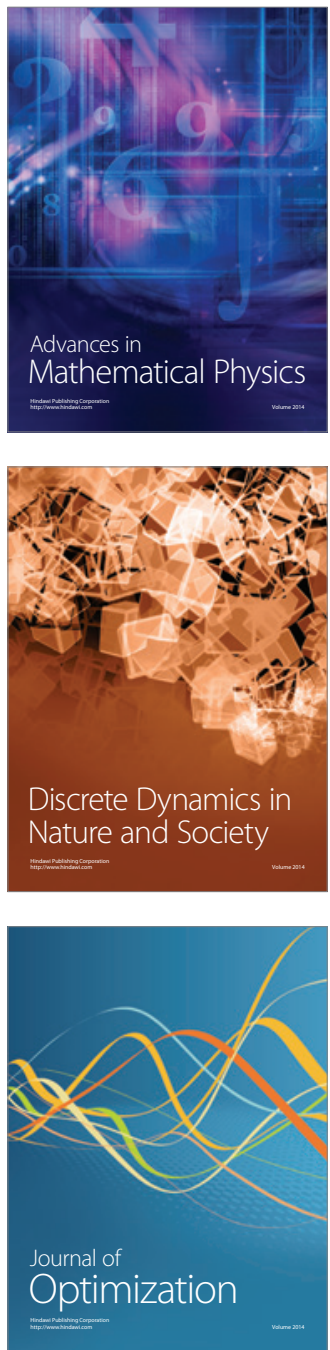